\title{
Preparation and Characterization of Ir Coating on Mo Network with a W Bond-Coat
}

\author{
Wang Xin, Yan Peng, Du Jihong, Li Zhengxian, Tang Yong, Yang Tao
}

Northwest Institute for Nonferrous Metal Research, Xi'an 710016, China

\begin{abstract}
A bi-layered Ir/W metallic coating was deposited onto the Mo network via a magnetron sputtering method. Results show that the sputtering $\mathrm{W}$ bond-coat is able to enhance the binding energy between the sputtering Ir coating and the Mo substrate, and virtually neither delamination nor peeling off is observed for the as-prepared coating. In addition, the interdiffusion between the $\mathrm{W}$ bond-coat and the Ir coating or the Mo substrate is not apparent. The dense and adherent Ir coating is identified to have a polycrystalline structure with (111) orientation. According to the three zone model suggested by Movchan and Demchishin for sputtering metallic coatings, the microstructure of the bi-layered metallic coating is consistent with the Zone 1 features. In fact, the bi-layered coating has very low lateral strength and inclines to crack under tension.
\end{abstract}

Key words: magnetron sputtering; Ir coating; W bond-coat; preferred growth; microstructure

Because of the exceptional strength and stiffness at high temperatures in conjunction with high thermal conductivity and low thermal expansion, the refractory metal molybdenum (Mo) and its alloys are widely used in aeronautic and astronautic fields in addition to other high temperature applications ${ }^{[1-3]}$. However, they are susceptible to high temperature oxidation and exhibit a strong degradation in air ${ }^{[4-6]}$. The oxidation of Mo follows a parabolic law between $250 \sim 450{ }^{\circ} \mathrm{C}$, and it changes into a linear law above $400{ }^{\circ} \mathrm{C}$. At the temperature of $300{ }^{\circ} \mathrm{C}$, Mo is oxidized into $\mathrm{MoO}_{2}$ and it suffers a further oxidation at $600{ }^{\circ} \mathrm{C}$ to form $\mathrm{MoO}_{3}$, which is volatilized at $750{ }^{\circ} \mathrm{C}$. Furthermore, high vaporization of $\mathrm{MoO}_{3}$ leads to an extremely large mass loss and high oxidation rates above the temperature of $650{ }^{\circ} \mathrm{C}$. Therefore, increasing the oxidation resistance of the refractory metal Mo and its alloys is crucial for their high-temperature applications in oxidizing environments.

Besides alloying with another oxidation resistant element, the oxidation resistance of Mo and its alloys can be greatly improved by applying high temperature protection coatings ${ }^{[4-12]}$. In addition to the classic silicide coatings prepared by diffusion process, the noble metallic iridium (Ir) coating turns out to be an effective oxygen barrier due to its low oxygen permeability up to $2100{ }^{\circ} \mathrm{C}$ together with its high melting temperature of 2440 ${ }^{\circ} \mathrm{C}^{[13-24]}$. Among the various preparation methods of Ir coating, magnetron sputtering is proved to be suitable for Ir deposition without introducing other impurities ${ }^{[25,26]}$. However, weak adhesion between the coating and the substrate was generally reported $^{[25,27]}$. Thus, increasing the binding energy between the Ir coating and the underlying Mo substrate becomes significant for improving the performance of the Ir coating.

Preparing a metallic interlayer between the substrate and the Ir coating as bond-coat may solve the above problems smoothly. In the present investigation, tungsten (W) was selected as the interlayer and was deposited onto the Mo substrate by magnetron sputtering before the preparation of the Ir coating. At last, a bi-layered metallic coating was prepared on the Mo net-work, and its microstructure was characterized in-situ.

\section{Experiment}

Molybdenum networks with purity of $99.9 \%$ were used as

Received date: November 25,2015

Foundation item: National High Technology Research and Development Program of China (“863” Program) (2012AA03A512); National Key Basic Research Program of China ("973" Program) (2012CB625100); National Natural Science Foundation of China (51501155)

Corresponding author: Wang Xin, Ph. D., Corrosion and Protection Center, Northwest Institute for Nonferrous Metal Research, Xi'an 710016, P. R. China, Tel: 0086-29-86283410, E-mail: wangx@alum.imr.ac.cn 
Table 1 Typical deposition parameters

\begin{tabular}{|c|c|c|c|c|c|c|c|}
\hline Coating & Ar gas/Pa & Bias voltage/V & Bias duty & Arc current/A & Arc voltage/V & Time/min & Temperature $/{ }^{\circ} \mathrm{C}$ \\
\hline Bombardment cleaning & 0.37 & 1200 & 80 & 2 & 410 & 10 & $200 \pm 20$ \\
\hline W-interlayer & 0.40 & 100 & 60 & 2 & $355 \sim 382$ & 360 & $200 \pm 20$ \\
\hline Ir Coating & 0.40 & 100 & 60 & 1.5 & 505 & 120 & $200 \pm 20$ \\
\hline
\end{tabular}

the substrates. Before deposition, the Mo substrates were washed within $25 \% \mathrm{HF}+75 \% \mathrm{HNO}_{3}$ diluted solutions and then ultrasonically cleaned within distilled water. The bi-layered metallic coating was continuously deposited by magnetron sputtering using cathode targets of $\mathrm{W}$ and Ir with purity of $99.99 \%$. The base pressure in the vacuum chamber was evacuated to $6 \times 10^{-3} \mathrm{~Pa}$, and the specimens were sputter-cleaned for $10 \mathrm{~min}$ to remove any possible contaminant layers in order to ensure good adhesion of deposited coatings. During deposition, inert gas (Ar, 99.99\%) was introduced into the chamber using the mass-flow controller, and the working pressure of the argon gas was set as $4 \times 10^{-1} \mathrm{~Pa}$. For comparison, specimens with mere $\mathrm{W}$ coating were prepared as well. The typical parameters are listed in Table 1.

The surface and cross-sectional morphology of the Ir coating was characterized by scanning electron microscopy (SEM, JSM-6460), and the chemical compositions of the metallic coatings were examined by the equipped energy dispersive spectroscopy (EDS). The phase identification and growth direction of the Ir coating were determined by X-ray diffraction (XRD, D/max, $\mathrm{Cu} \mathrm{K \alpha}$ radiation at $40 \mathrm{kV}$ ) at a scanning rate of $4^{\circ} /$ min from $20^{\circ}$ to $90^{\circ}$ of $2 \theta$.

\section{Results and Discussion}

\subsection{Deposition of $\mathrm{W}$ bond-coat}

Fig.1a shows the surface morphology of the $\mathrm{W}$ bond-coat (BC). It can be observed that the surface of the $\mathrm{W}$ bond-coat is coarse with some protuberances on the surface, which is beneficial for improving the binding energy between the $\mathrm{Ir}$ coating and $\mathrm{BC}$ by mechanical interlocking. Fig. $1 \mathrm{~b}$ and $1 \mathrm{c}$ display the back-scattered electron image of the crosssectional microstructure and the corresponding EDS linear scan results, respectively. It can be seen that the interface between $\mathrm{BC}$ and the Mo substrate is undulating, which is caused by the pre-treatment of the substrate. Besides, the interface is clear-cut, indicating that the interdiffusion between $\mathrm{BC}$ and the Mo substrate is not apparent during the BC preparation process. This is consistent with the EDS linear scan results.

\subsection{Microstructure of Ir coating}

Fig.2a exhibits the surface morphology of the bi-layered Ir/W coating. It is similar to the typical surface morphology of the metallic coatings deposited by magnetron sputtering, and there are some cracks on the surface of the Ir coating, which reflect the inter-columnar gaps within the Ir coating. Fig.2b and $2 \mathrm{c}$ shows the cross-sectional microstructure of the bi-layered metallic coating and the corresponding EDS linear scan results, respectively. It can be seen that the Ir coating adheres to the underlying $\mathrm{W}$ interlayer very well. According to the EDS linear scan results, the interdiffusion between the Ir coating and the $\mathrm{W}$ interlayer is not obvious during deposition.

Fig. 3 shows the XRD pattern of the Ir coating, which reveals that the Ir coating has a polycrystalline structure. Compared with the standard JCPDS file (46-1044), the XRD pattern exhibits strong diffraction peaks at $40.50^{\circ}, 47.18^{\circ}$, $69.04^{\circ}, 83.18^{\circ}$ and $87.78^{\circ}$, corresponding to the (111), (200), (220), (311) and (222) crystal faces, respectively. However, it can be seen that the diffraction peak of (111) crystal face is much stronger than other ones, suggesting the preferred growth of the Ir coating during deposition. The texture coefficient (TC) for a given plane, which can give the information of the strongest reflection along the $(h k l)$ plane at different

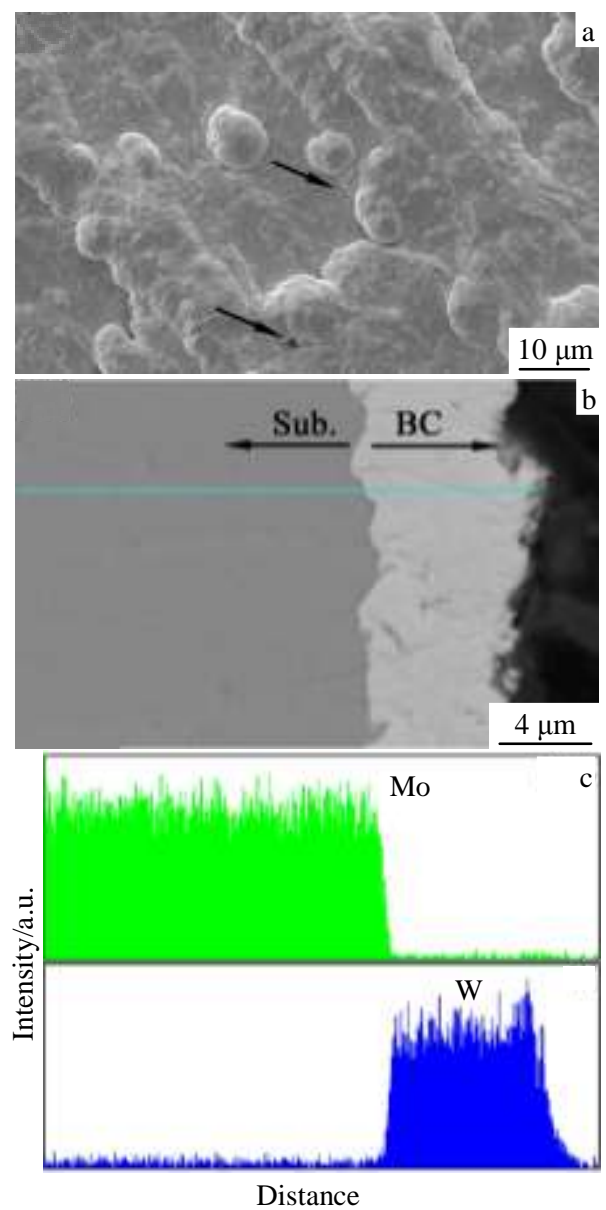

Fig.1 Surface morphology (a) and cross-sectional microstructure (b) of the sputtering $\mathrm{W}$ bond-coat with the corresponding linear scanning EDS results (c) 


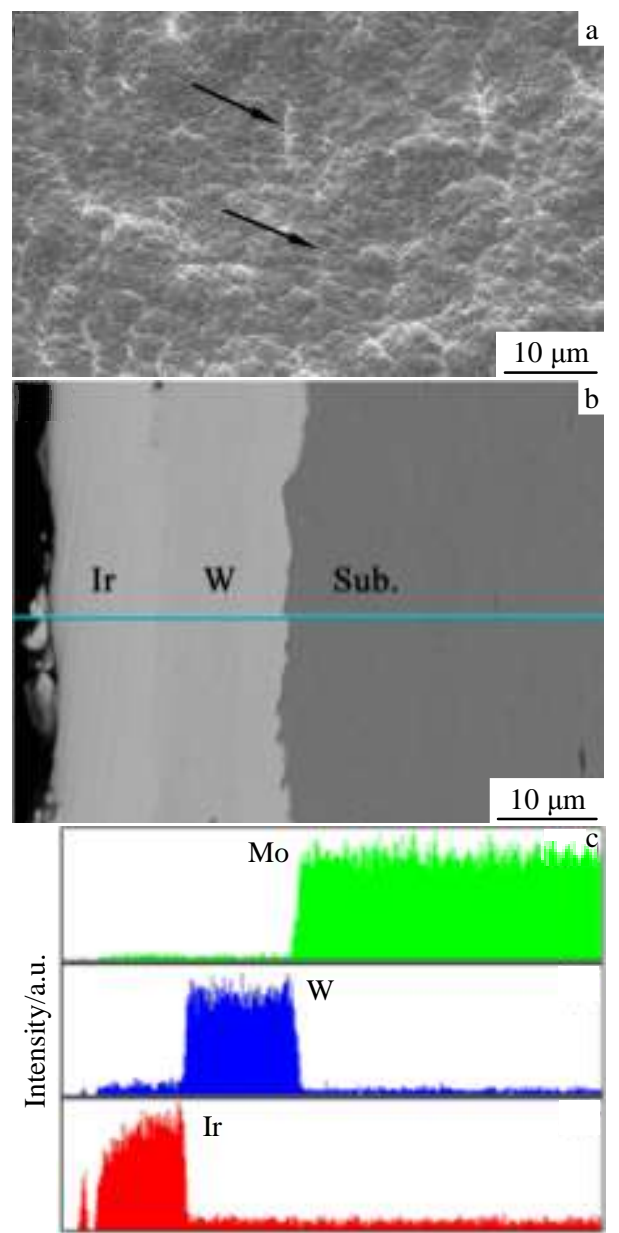

Distance

Fig.2 Surface morphology (a) and cross-sectional microstructure (b) of the sputtering bi-layered metallic Ir/W coating with the corresponding linear scanning EDS results (c)

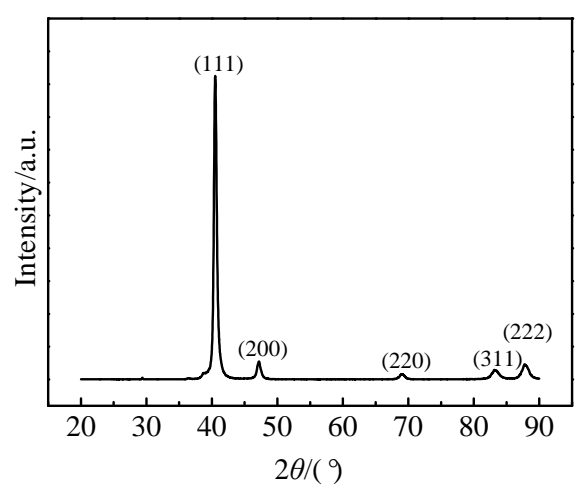

Fig.3 X-ray diffraction pattern of the sputtering Ir coating

conditions, can be calculated via the following equation ${ }^{[28]}$ :

$$
\mathrm{TC}_{(h k l)}=\frac{I_{(h k l)} / I_{0(h k l)}}{1 / N\left[\sum I_{(h k l)} / I_{0(h k l)}\right]}
$$

where, $\mathrm{TC}_{(h k l)}$ is the texture coefficient of the $(h k l)$ plane, $I_{(h k l)}$ is the measured intensity of $(h k l)$ plane, $I_{0(h k l)}$ is the corresponding recorded intensity in JCPDS file, and $N$ is the number of preferred growth directions. From the calculation, $\mathrm{TC}_{(111)}, \mathrm{TC}_{(200)}, \mathrm{TC}_{(220)}, \mathrm{TC}_{(311)}$ and $\mathrm{TC}_{(222)}$ are about 1.522, $0.167,0.065,0.088$ and 0.472 , respectively, indicating that the deposited Ir coating has preferential growth orientation of (111) crystal plane.

\subsection{Coating deposition on Mo networks}

Fig.4a and 4b show the SEM images of the Mo networks after coatings deposition of $\mathrm{W}$ and $\mathrm{Ir} / \mathrm{W}$, respectively. It can be seen that the metallic coating on the network is intact and neither crack nor spallation is observed, implying that the binding energy between the $\mathrm{W}$ interlayer and the Ir coating is satisfactory.

Fig.5 shows the in-situ observation of the cross-sectional microstructure. The bi-layered metallic coating exhibits columnar morphology with gaps between the columns, and this is consistent with the observation in Fig.2. It can be seen that a crack forms, within the bi-layered metallic coating as denoted by the black arrow. Besides, no delamination is found at the Ir/W or the W/Mo interface. In addition, it is very interesting that the Ir columnar granules seem to grow just along the underlying $\mathrm{W}$ coating. In other words, the upper Ir coating and the underlying $\mathrm{W}$ bond-coat possess the similar microstructure, and they compose the whole columnar grain together.

\section{Discussion}

\subsection{Effect of $W$ interlayer}

In order to protect the Mo substrate from high temperature oxidation, the metallic Ir coating should not only be integrity but also bond well to the substrate. However, because of the large thermal expansion coefficient (CTE) mismatch between

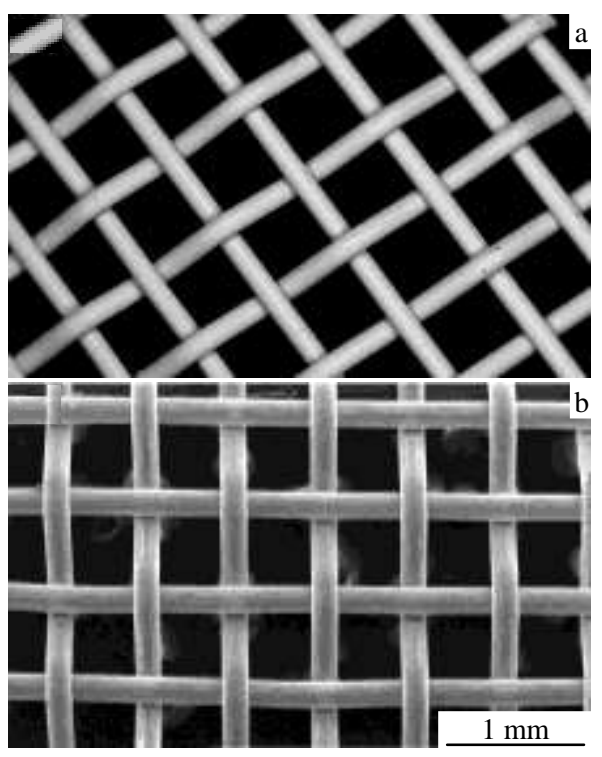

Fig.4 Surface morphologies of the Mo networks after deposition of $\mathrm{W}$ (a) and $\mathrm{Ir} / \mathrm{W}$ (b) 

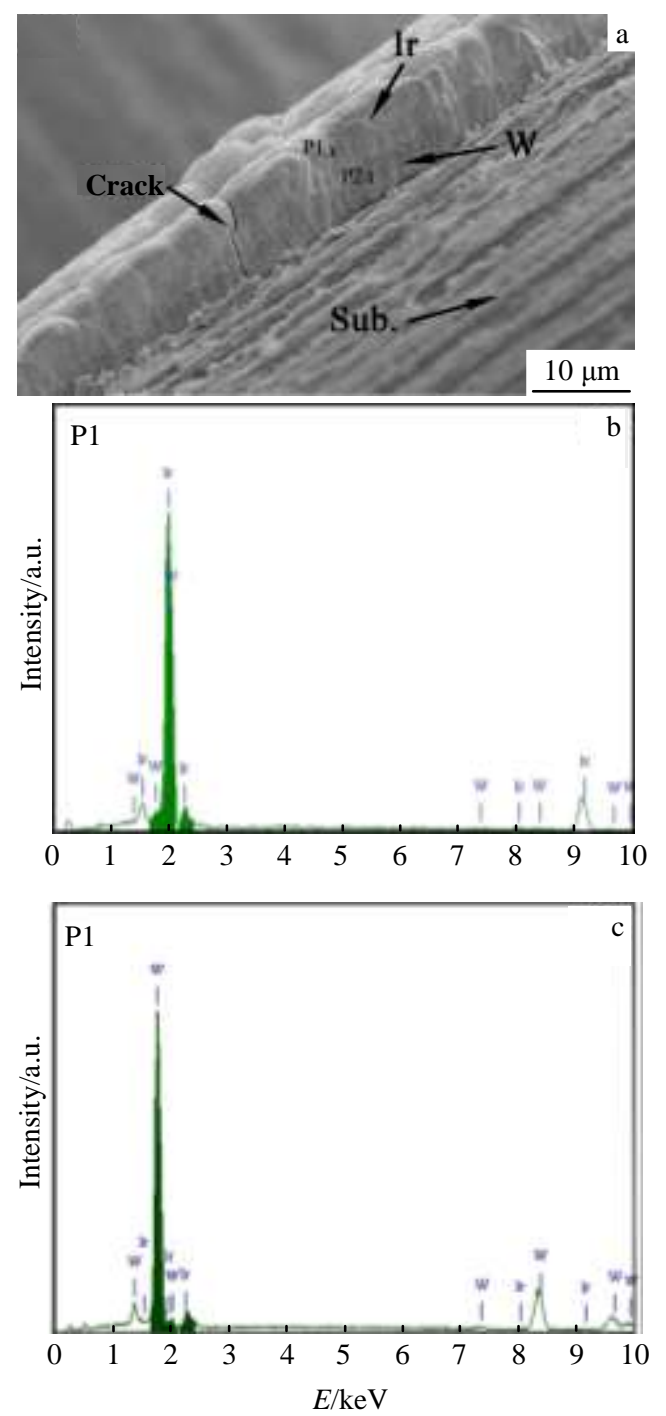

Fig.5 In-situ observation of the bi-layered Ir/W coating on the Mo network (a) and the corresponding EDS spectra (b, c)

the Mo substrate $\left(4.9 \times 10^{-6}{ }^{\circ} \mathrm{C}^{-1}\right)$ and the sputtering $\mathrm{Ir}$ coating $\left(6.2 \times 10^{-6}{ }^{\circ} \mathrm{C}^{-1}{ }^{[27]}\right)$ as well as their large lattice mismatch resulting from the various crystal structures, large stresses form during deposition, which cause the delamination and peeling off of the as-prepared Ir coating. In order to increase the binding energy between the coating and the substrate, $\mathrm{W}$ was applied as the bond-coat because both Ir and Mo can dissolve into the $\mathrm{W}$ bond-coat. Particularly, Mo and $\mathrm{W}$ can form a continuous series of solid solutions with a bcc structure at all temperatures without forming brittle intermetallics at interfaces. Furthermore, although $\mathrm{W}$ possesses the bcc (body-centered cubic) crystal structure, the $\mathrm{W}$ films in the scale of micrometer or nanometer display ductility to some extent. Thus, the thermal stress might be released through the plastic deformation of the interlayer. These are beneficial for improving the adherence of the sputtering Ir coating to the Mo substrate. Virtually, neither delamination nor peeling off of the
Ir coating is observed due to the application of $\mathrm{W}$ interlayer (Fig.4).

\subsection{Preferred growth of Ir coating}

Because the surface free energy of (111) crystal face is the lowest due to the greatest density of the lattice point, the (111) plane is easily oriented in the case of fcc (face-centered cubic) crystal structure metallic coatings prepared by physical vapor deposition (PVD) methods. However, other orientation can also form in the Ir coating preparation by other methods ${ }^{[13,29]}$. In this investigation, three other factors should be taken into consideration for the (111) orientation of the sputtering Ir coating.

(1) The lattice mismatch between W (bcc, $a=0.3165 \mathrm{~nm}$ ) and $\operatorname{Ir}$ (fcc, $a=0.3839 \mathrm{~nm}$ ) is about $18 \%$. Because the large mismatch could make the effect of the coherence energy at the interface negligible, the effect of the crystal structure of the W interlayer on the preferred orientation could be disregarded. Furthermore, although the sputtering $\mathrm{Ir}$ coating is continuously deposited onto the $\mathrm{W}$ interlayer, the rough surface of the W interlayer with considerable defects (as depicted by black arrows in Fig.1) is not suitable for the epitaxial growth of the sputtering Ir coating. Instead, this morphology could facilitate the (111) orientation of the sputtering Ir coating ${ }^{[29]}$.

(2) The deposition rate is enough high for the formation of (111) orientation of the Ir coating. In this investigation, the deposition rate of the sputtering Ir coating is about $90 \mathrm{~nm} / \mathrm{min}$. At this high deposition rate, the time for the immigration time of Ir adatoms is very short, which makes the formation of (111) orientation in the deposited Ir film very easy. Moreover, the substrate temperature (about $200{ }^{\circ} \mathrm{C}$ ) is too low for the adatoms to immigration.

(3) The as-deposited Ir atoms hardly suffer the bombardment from the high-energy ions during deposition. This is beneficial for the aggregation of Ir atoms on the surface of the $\mathrm{W}$ interlayer ${ }^{[29]}$, and then induce the formation of (111) orientation.

\subsection{Microstructure formation of the bi-layered metallic coating}

In this investigation, the ratios of the deposition temperature (about $200{ }^{\circ} \mathrm{C}$ ) to the melting temperature of $\mathrm{W}\left(3410{ }^{\circ} \mathrm{C}\right)$ and Ir $\left(2440{ }^{\circ} \mathrm{C}\right)$ are about 0.13 and 0.17 , respectively, and the argon pressure is set about $0.4 \mathrm{~Pa}$. According to the model proposed by Thornton for sputtering metallic coatings ${ }^{[30]}$, the microstructure of the sputtering coating should be consistent with Zone T. However, it can be concluded that the microstructure of the bi-layered metallic coating as displayed in Fig. 5 is more similar to Zone 1 of the model suggested by Movchan and Demchishin ${ }^{[30]}$. The deposited bi-layered metallic coating consists of tapered crystals with domed tops separated by voided boundaries. The formation of this microstructure can be attributed to the reason that the mobility of the atoms or particles is unable to overcome the effects of 
shadowing caused by the rough surface of the underlayer through rapid surface diffusion. Another point which is need to be mentioned is that the crystal diameter of the metallic deposits increases with $T / T_{\mathrm{m}}$ due to the very limited surface diffusion. Because the $T / T_{\mathrm{m}}$ value of $\mathrm{Ir}$ is much higher than that of W, it can be seen in Fig.5 that the crystal diameter of Ir is much larger than that of $\mathrm{W}$.

This specific microstructure makes the metallic coating have very low lateral strength, and it can be demonstrated by the crack formed within the bi-layered metallic coating as denoted by the black arrow in Fig.5. It is known that Ir has the properties similar to the metal with bcc structure, suggesting that Ir has high brittleness despite of its fcc crystalline structure. In general, bulk Ir material fails predominantly by brittle fracture of grain boundary under tension at room temperature because of the weak inter-granular strength ${ }^{[27]}$. Thus, it is best for the as-prepared Ir coating to be in compressive stress state for practical application. In this investigation, the thermal expansion coefficient (CTE) of both the Mo substrate $\left(4.9 \times 10^{-6}{ }^{\circ} \mathrm{C}^{-1}\right)$ and the $\mathrm{W}$ interlayer $\left(4.5 \times 10^{-6}\right.$ $\left.{ }^{\circ} \mathrm{C}^{-1}{ }^{[17]}\right)$ is much lower than that of the sputtering Ir coating. This implies that the as-prepared Ir coating is in tensile stress state, and inclines to crack under tensile stress. Furthermore, as stated above, the inter-columnar link is much weaker compared with the intra-columnar strength. Therefore, cracks are very easy to form during the specimen preparation process. The crack denoted by the black arrow in Fig.5 probably nucleates at the inter-columnar interface and propagates along the inter-columnar gap during the specimen preparation process. Therefore, it was better for the bi-layered coating to have a vacuum annealing process before practical application.

\section{Conclusions}

1) Dense and adherent Ir coating is prepared on the surface of Mo network with a W bond-coat using the magnetron sputtering method.

2) The sputtering Ir coating has a polycrystalline structure with (111) orientation. Due to the application of the W bond-coat, neither delamination nor peeling off is observed for the as-prepared coating.

3) The bi-layered metallic coating exhibits typical Zone 1 features according to the three zone model suggested by Movchan-Demchishin, and has very low lateral strength.

\section{References}

1 Cockeram B V. Metall Mater Trans A[J], 2005, 36: 1777

2 Glenny E, Restall J E, Less J. Comm Metals[J], 1965, 9: 367

3 Park J J, Butt D P, Beard C A. Nucl Eng Design[J], 2000, 196: 315

4 Smolik G R, Petti D A, Schuetz S T. J Nucl Mater[J], 2000, 283-287: 1458

5 Ana M Espino, Luis A Diaz, Adolfo Fernandez et al. $J$ Am
Ceram Soc[J], 2005, 88(4): 1000

6 Chakraborty S P, Banerjee S, Sharma I G et al. Journal of Nuclear Materials[J], 2010, 403: 152

7 Ingemarsson L, Hellström K, Johansson L G et al. Intermetallics [J], 2011, 19: 1319

8 Stergiou A, Tsakiropoulos P. Intermetallics[J], 1997, 5: 117

9 Hellström K, Tang J E, Jonsson T et al. Journal of the European Ceramic Society[J], 2009, 29: 2105

10 Cook J, Khan A, Lee E et al. Materials Science and Engineering $A[\mathrm{~J}], 1992,155: 183$

11 Ingemarsson L, Halvarsson M, Hellstroma $\mathrm{K}$ et al. Intermetallics [J], 2010, 18: 77

12 Liu Y Q, Shao G, Tsakiropoulos P. Intermetallics[J], 2001, 9: 125

13 Wang Liangbing, Chen Zhaofeng, Zhang Ying et al. International Journal of Refractory Metals and Hard Materials [J], 2009, 27: 590

14 Kang N Lee, Wayne L Worrell. Oxidation of Metals[J], 1989, 32: 357

15 Bao Z B, Murakami H, Yamabe-Mitarai Y. Corrosion Science[J], 2011, 53: 1224

16 Cong Xiangna, Chen Zhaofeng, Wu Wangping et al. Applied Surface Science[J], 2012, 258: 5135

17 Wu Wangping, Chen Zhaofeng, Cheng Han et al. Applied Surface Science[J], 2011, 257: 7295

18 Bao Z B, Murakami H, Yamabe-Mitarai Y. Corrosion Science[J], 2014, 87: 306

19 Chen Zhaofeng, Wu Wangping, Cong Xiangna. J Mater Sci Technol [J], 2014, 30(3): 268

20 Yoko Yamabe-Mitarai, Hideyuki Murakami. Intermetallics[J], 2014, 48: 86

21 Zhu Li'an, Bai Shuxin, Zhang Hong et al. International Journal of Refractory Metals and Hard Materials[J], 2014, 44: 42

22 Wang Liangbing, Chen Zhaofeng, Zhang Ying et al. International Journal of Refractory Metals and Hard Materials [J], 2009, 27: 590

23 Huang Yongle, Bai Shuxin, Zhang Hong et al. International Journal of Refractory Metals and Hard Materials[J], 2015, 50: 204

24 Clift W M, McCarty K F, Boehme D R. Surface and Coatings Technology[J], 1990, 42: 29

25 Jan Hagen, Frank Burmeister, Alexander Fromm et al. Plasma Process Polym[J] 2009, 6: S678

26 Yoshio Abea, Eiji Watanabea, Katsutaka Sasakia et al. Surface and Coatings Technology[J], 2005, 198: 148

27 Zhu Li'an, Bai Shuxin, Zhang Hong et al. Surface and Coatings Technology [J], 2013, 235: 68

28 Patil P S, Chigare P S, Sadale S B et al. Mater Chem Phys[J], 2003, 80: 667

29 Tran Dang Khoa, Sadayoshi Horii, Susumu Horita. Thin Solid Films[J], 2002, 419: 88

30 Thornton John A. Ann Rev Mater Sci[J], 1977, 7: 239 


\title{
Mo 丝网上双层 Ir/W 高温抗氧化涂层的制备与表征
}

\author{
汪 欣, 严 鹏, 杜继红, 李争显, 唐 勇, 杨 涛 \\ (西北有色金属研究院，陕西 西安 710016)
}

\begin{abstract}
摘 要: 为改善浌射依涂层与钼基体之间的结合力, 在钼基体与依涂层之间制备了铇粘结层, 并成功在钼丝网上制备了双层的铱/铇涂 层。研究表明，铇粘结层的制备能有效改善铱涂层与钼基体之间的结合力，从而有效抑制铱涂层的剥落。对于制备态的样品，W 粘结层 与铱涂层以及钼基体之间未出现明显的互扩散。 $\mathrm{X}$ 射线衍射结果表明, 溅射铱涂层为多晶结构且呈（111）择优取向生长。根据 Movchan-Demchishin 模型, 所制备的双层铱/铇涂层的显微结构与“1 区”结构类似, 该结构表明所制备的涂层横向结合力弱, 在拉应力状 态下易发生开裂。
\end{abstract}

关键词：磁控溅射；依涂层；铇粘结层；择优生长；显微结构

作者简介: 汪 欣, 男, 1987 年生, 博士, 西北有色金属研究院腐蚀与防护研究所, 陕西 西安 710016, 电话: 029-86283410, E-mail: wangx@alum.imr.ac.cn 